\title{
Keanekaragaman Tanaman Pisang (Musa spp) di Kecamatan Secanggang, Kabupaten Langkat, Sumatera Utara
}

\author{
Eva Saulina Sihotang ${ }^{1}$, Budi Waluyo ${ }^{1 *}$
}

\author{
${ }^{1}$ Jurusan Budidaya Pertanian, Fakultas Pertanian, Universitas Brawijaya, Malang 65145 \\ budiwaluyo@ub.ac.id
}

\begin{abstract}
Abstrak
Produksi pisang di Indonesia pada tahun 2018 sebesar 7,2 juta ton atau mengalami peningkatan sebesar 101.703 ton dibandingkan tahun 2017. Sementara itu produksi pisang di Provinsi Sumatera Utara pada tahun 2018 yaitu sebesar 118.648 ton. Saat ini belum diketahui secara pasti berapa jenis pisang yang ditanam oleh masyarakat, meskipun diperoleh data yang cukup tentang luas panen dan produksi pisang. Eksplorasi, inventarisasi, dan pelestarian plasma nutfah pisang di Indonesia sangat terbatas. Tujuan dari penelitian ini adalah untuk mengetahui keanekaragaman dan untuk karakterisasi morfologi tanaman pisang di Kecamatan Secanggang, Kabupaten Langkat, Provinsi Sumatra Utara. Penelitian dilakukan pada bulan Februari 2020 - April 2020. Penelitian dilakukan di 14 desa pada Kecamatan Secanggang, Kecamatan Secanggang, Kabupaten Langkat, Provinsi Sumatra Utara. Bahan yang digunakan adalah seluruh bagian tanaman pisang. Penentuan sampel dalam penelitian menggunakan rancangan sampling nonprobabilitas dengan metode Purposive sampling. Data yang diperoleh diolah secara tabulasi dan dianalisis secara deskriptif. Keanekaragaman pisang dihitung dengan rumus indeks keanekaragaman ( $\left.\mathrm{H}^{\prime}\right)$ Shannon-Wiener dan dominansi dihitung dengan rumus indeks dominansi (C). Berdasarkan hasil pengamatan menunjukkan bahwa keanekaragaman pisang di Kecamatan Secanggang, ditemukan 8 genotipe pisang yaitu Pisang Barangan, Pisang Nangka, Pisang Banten, Pisang Lilit Tandan, Pisang Kepok, Pisang Tanduk, Pisang Awak, dan Pisang Raja. Setiap genotipe yang ditemukan memiliki karakter morfologi yang berbeda. Kecamatan Secanggang memiliki keanekaragaman tanaman pisang yang sedang dengan nilai indeks keanekaragaman ( $\left.\mathrm{H}^{\prime}\right)$ 0-1,74 dan nilai indeks dominansi (C) 0,18-1.
\end{abstract}

Kata kunci: Dominansi, genotip, keanekaragaman, pisang, Secanggang.

\section{Pendahuluan}

Pisang merupakan komoditi yang cukup menarik untuk dikembangkan dan ditingkatkan produksinya, jika ditinjau dari aspek perdagangan internasional. Namun, Indonesia yang tercatat sebagai Negara produsen ranking ke-enam dunia, belum tercatat sebagai Negara eksportir. Negara-negara importir buah pisang yang juga menjadi eksportir adalah Belgia, Amerika Serikat, Jerman, dan Francis (Rusdiansyah, 2013).

Produksi pisang di Indonesia pada tahun 2018 sebesar 7.264.383 ton atau mengalami peningkatan

\section{Abstract}

Banana production in Indonesia in 2018 was 7.2 million tons or an increase of 101.703 tons compared to 2017. Meanwhile, banana production in North Sumatra Province in 2018 was 118.648 tons. Currently, it is not known exactly how many types of bananas are planted by the community, although sufficient data is obtained on harvested area and banana production. Exploration, inventory, and conservation of banana germplasm in Indonesia is very limited. The purpose of this study was to determine the diversity and to characterize the morphology of banana plants in Secanggang District, Langkat Regency, North Sumatra Province. The study was conducted in February 2020 - April 2020. The study was conducted in 14 villages in Secanggang District, Langkat Regency, North Sumatra Province. The material used is all parts of the banana plant. Determination of the sample in the study using a non-probability sampling design with purposive sampling method. The data obtained were processed by tabulation and analyzed descriptively. Banana diversity was calculated using the Shannon-Wiener diversity index formula $\left(H^{\prime}\right)$ and dominance was calculated using the dominance index formula $(C)$. The findings of the observations revealed that there are eight genotypes of bananas in Secanggang District., namely Pisang Barangan, Pisang Nangka, Pisang Banten, Pisang Lilit Tandan, Pisang Kepok, Pisang Tanduk, Pisang Awak, dan Pisang Raja. Each genotype found has different morphological characters. Secanggang District has a moderate diversity of banana plants with a diversity index value $\left(H^{\prime}\right)$ 0-1.74 and a dominance index value $(C)$ 0.18-1.

Keywords: Banana, diversity, dominance, genotype, Secanggang.

sebesar 101.703 ton dibandingkan tahun 2017. Sementara itu produksi pisang di Provinsi Sumatera Utara pada tahun 2018 yaitu sebesar 118.648 ton. Sumatera Utara merupakan provinsi penghasil pisang terbesar ketiga di Sumatera setelah provinsi Sumatera Selatan. Di Sumatera Utara, pisang merupakan tanaman buah dengan produksi paling tinggi kedua setelah pepaya (Badan Pusat Statistik, 2020). Langkat merupakan kabupaten dengan produksi pisang tertinggi di Provinsi Sumatera Utara yaitu 598.136 kuintal pada tahun 2018. Kecamatan Secanggang merupakan salah satu dari 23 kecamatan yang terdapat di Kabupaten Langkat. Kecamatan 
Secanggang dikenal dengan produk kripik sale pisang dan klaras (daun tanaman pisang).

Saat ini belum diketahui secara pasti berapa jenis pisang yang ditanam oleh masyarakat, meski diperoleh data yang cukup tentang luas panen dan produksi pisang, Eksplorasi, inventarisasi, dan pelestarian plasma nutfah pisang di Indonesia sangat terbatas. Hal ini disebabkan koleksi tanaman pisang saat ini berada di tempat yang terpencar-pencar. Keadaan ini menyebabkan pengelolaan tanaman koleksi menjadi tidak optimal dan sering tidak akurat data karakteristik varietas atau klon (Sukartini, 2006).

Karakterisasi dilakukan untuk mengetahui sifat morfologis dan agronomis tanaman, selain juga bertujuan untuk meniadakan duplikasi pada koleksi plasma nutfah. Tanaman pisang memiliki keanekaragaman tinggi, maka kemungkinan terjadinya permasalahan adanya nama yang sama, tetapi genom berbeda ataupun sebaliknya sangat mungkin terjadi. Deskripsi yang dimiliki dapat menjadi suatu asset serta koleksi bagi bidang pertanian dan juga dapat menjadi suatu referensi bagi yang memerlukan. Tujuan dari penelitian ini adalah untuk mengetahui keanekaragaman tanaman pisang di Kecamatan Secanggang dan untuk mengkarakterisasi tanaman pisang di Kecamatan Secanggang berdasarkan morfologi.

\section{Bahan dan Metode}

Penelitian dilakukan pada Februari 2020 - April 2020. Penelitian dilakukan di 14 desa pada Kecamatan Secanggang, Sumatera Utara yang meliputi Desa Cinta Raja, Desa Jaring Halus, Desa Karang Anyar, Desa Karang Gading, Desa Kebun Kelapa, Desa Kepala sungai, Desa Kwala Besar, Desa Pantai Gading, Desa Perkotaan, Desa Secanggang, Desa Selontong, Desa Suka Mulia, Desa Sungai Ular, Desa Telaga Jernih, Desa Teluk di Kabupaten Langkat, Provinsi Sumatera Utara.

Alat yang digunakan meliputi meteran, penggaris, kamera digital, buku panduan deskriptor pisang IPGRI (International Plant Genetic Resources Institute, 1996) dan alat tulis. Bahan yang digunakan adalah seluruh bagian tanaman pisang.

Penelitian dilakukan dengan metode deskriptif. Penentuan sampel menggunakan rancangan sampling non-probabilitas dengan metode purposive sampling Metode ini adalah metode pengambilan sampel dengan cara; (1) memilih individu-individu tertentu karena dianggap memenuhi kriteria, (2) berdasarkan penilaian tertentu, (3) mewakili statistik serta memiliki informasi yang diperlukan bagi penelitinya. Data yang diperoleh diolah secara tabulasi dan dianalisis secara deskriptif. Keanekaragaman pisang dihitung dengan rumus indeks keanekaragaman $\left(\mathrm{H}^{\prime}\right)$ Shannon-Wiener (Magurran, 1998), lalu untuk mengukur dominansi dihitung dengan rumus indeks dominansi (C).
Untuk memperoleh informasi mengenai keragaman pisang serta informasi lain yang berkaitan dengan penelitian, maka dilakukan kegiatan pengumpulan data primer dan sekunder. Data primer diperoleh secara langsung dari lokasi penelitian sehingga dapat memberi gambaran analisis terhadap objek yang diteliti melalui data sampel tanaman yang berada di lokasi penelitian. Sedangkan data sekunder diperoleh dengan mengumpulkan data dari Kantor Balai Penyuluhan Pertanian (BPP) di kecamatan yang dijadikan daerah penelitian.

Penelitian dilakukan dengan menentukan wilayah responden di Kecamatan Secanggang yang memiliki kebun pisang. Adapun tujuan dari survei pendahuluan ini adalah untuk mengetahui lokasi keberadaan pisang dan mempermudah pada saat melakukan pengamatan di lapang.

Sampel yang digunakan yaitu pisang yang memiliki ciri morfologi lengkap yaitu pisang yang memiliki bagian vegetatif (batang semu, daun, anakan) dan bagian reproduktif (bunga, buah, biji jika ada) (Jumari dan Pudjoarianto, 2000). Data yang diperlukan dari setiap desa adalah data jenis Pisang, Jumlah dusun, batas setiap dusun dan nama petani pisang setelah memperoleh data tersebut, maka dilakukan wawancara dan pengamatan pada 16 lokasi di Kecamatan Secanggang.

Pengambilan sampel tanaman dalam satu lokasi pengamatan sangat sedikit dikarenakan tanaman yang mempunyai organ-organ lengkap (batang, daun, braktea/jantung pisang dan bunga) cukup jarang, sehingga pada satu lokasi pengamatan hanya diambil 2-3 sampel tanaman. Penentuan responden untuk wawancara didasarkan pada pengetahuan tentang keragaman pisang dan semua aspek yang berkaitan dengan tanaman pisang yang berada pada setiap lokasi pengamatan. Tanaman pisang dengan karakter berbeda dijadikan sampel. Karakter - karakter penting yang akan hilang di lapangan didokumentasikan dengan menggunakan kamera.

Pengamatan morfologi dilakukan berdasarkan pedoman karakter morfologi pisang dari IPGRI (Internasional Plant Genetic Resources Institute, 1996). Karakter yang diamati pada kegiatan ini terdiri dari karakter vegetatif dan karakter generatif. Pengamatan dilakukan terhadap seluruh bagian tanaman pisang yang meliputi batang semu, daun, bunga dan buah.

Data yang diperoleh dari hasil eksplorasi pisang di lapangan diolah secara tabulasi dan dianalisis secara deskriptif. Keanekaragaman pisang yang tumbuh di Kecamatan Secanggang dihitung dengan menggunakan indeks keanekaragaman (H') ShannonWiener (Magurran, 1998).

$$
H^{\prime}=-\sum_{i=1}^{s} p i L n p i
$$


Keterangan: $\mathrm{H}^{\prime}=$ Indeks keanekaragaman; $\mathrm{Pi}=$ ni $/ \mathrm{N}$; $\mathrm{Ni}=$ jumlah individu jenis ke $\mathrm{i}$; $\mathrm{N}=$ Jumlah individu semua jenis

kisaran total indeks keanekaragaman dapat diklasifikasi sebagai berikut:

$\mathrm{H}^{\prime}<1,0=$ keanekaragaman rendah

$1,0<\mathrm{H}^{\prime}<3,322=$ keanekaragaman sedang

$\mathrm{H}^{\prime}>3,322=$ keanekaragaman tinggi.

Untuk mengukur dominansi suatu jenis pisang dilakukan perhitungan indeks dominansi (C).

$$
C=\sum_{i=1}^{\mathrm{a}}(p i)^{2}
$$

Keterangan: Pi: ni/N

\section{Hasil dan Pembahasan}

Berdasarkan hasil eksplorasi di Kecamatan Secanggang di 14 Desa didapatkan 8 genotipe pisang. Delapan genotipe pisang yang ditemukan merupakan genotipe asli dan unggulan dari Kecamatan Secanggang. Hal yang sama ditunjukkan oleh Prasetyo dan Sudiono (2004), kultivar pisang yang banyak tumbuh di Kabupaten Langkat khususnya pada Kecamatan Secanggang adalah pisang Kepok, Raja, Nangka, dan pisang Tanduk. Berdasarkan hasil pengamatan terhadap penampilan karakter morfologi pada organ vegetatif dan generatif diketahui adanya keragaman dalam bentuk, ukuran, warna maupun karakter lainnya.

Tabel 1. Karakteristik Morfologi Tanaman Pisang di Kecamatan Secanggang, Kabupaten Langkat

\begin{tabular}{|c|c|c|c|c|}
\hline \multirow{2}{*}{ Karakter } & \multicolumn{4}{|c|}{ Jenis Pisang } \\
\hline & Barangan & Lilit Tandan & Raja & Awak \\
\hline 1 & $2.1-2.9 \mathrm{~m}$ & $3 \mathrm{~m}$ & $2.1-2.9 \mathrm{~m}$ & $4.5 \mathrm{~m}$ \\
\hline 2 & Hijau kemerahan & Merah keunguan & Hijau kemerahan & Hijau kekuningan \\
\hline 3 & Lebar & Kecil & Tersebar & Sedikit \\
\hline 4 & Coklat gelap & Coklat & Coklat kehitaman & Coklat kehitaman \\
\hline 5 & Terbuka. batas menyebar & Terbuka. batas tegak & Lurus. batas tegak & Melengkung ke dalam \\
\hline 6 & $70 \mathrm{~cm}$ & $50 \mathrm{~cm}$ & $63 \mathrm{~cm}$ & $65 \mathrm{~cm}$ \\
\hline 7 & Lonjong sedang & Lonjong sedang & Seperti gasing & Bulat telur \\
\hline 8 & Kecil & Besar & Kecil & Besar \\
\hline 9 & Menengah & Menengah & Menengah & tumpul \\
\hline 10 & Melengkung ke batang & Melengkung ke atas & Melengkung ke atas & Melengkung ke atas \\
\hline 11 & Lurus dibagian atas & Lurus dibagian atas & Lurus di bagian atas & Lurus di bagian atas \\
\hline 12 & Bagian atas tumpul & Seperti leher botol & Menunjuk & Seperti leher botol \\
\hline 13 & Model kokoh & Model kokoh & Model kokoh & Model kokoh \\
\hline 14 & Kuning gading & Kuning gading & Kuning gading & Kuning gading \\
\hline \multirow{2}{*}{ Karakter } & \multicolumn{4}{|c|}{ Jenis pisang } \\
\hline & Nangka & Banten & Kepok & Tanduk \\
\hline 1 & $3 \mathrm{~m}$ & $2.5 \mathrm{~m}$ & $6.5 \mathrm{~m}$ & $3-4 \mathrm{~m}$ \\
\hline 2 & Hijau kemerahan & Merah & Hijau tua & Hijau kekuningan \\
\hline 3 & Sedikit & Banyak & Lebar & Sedikit \\
\hline 4 & Coklat kehitaman & Coklat kehitaman & Coklat kehitaman & Coklat gelap \\
\hline 5 & Terbuka batas tegak & Terbuka batas tegak & Lurus batas tegak & melengkung ke dalam \\
\hline 6 & $52 \mathrm{~cm}$ & $52 \mathrm{~cm}$ & $63 \mathrm{~cm}$ & $63 \mathrm{~cm}$ \\
\hline 7 & Lonjong sedang & Seperti gasing & Bulat telur & Lonjong \\
\hline 8 & Besar & Besar & Medium & Besar \\
\hline 9 & Menengah & Menunjuk & Tumpul membagi & Sedikit menunjuk \\
\hline 10 & Melengkung ke atas & Tegak lurus tangkai & Melengkung ke atas & Melengkung ke batang \\
\hline 11 & Lurus dibagian atas & Lurus & Lurus di bagian atas & Lurus di bagian atas \\
\hline 12 & Leher botol & atas tumpul & atas tumpul & Menunjuk panjang \\
\hline 13 & Model kokoh & Model kokoh & Model kokoh & Dasar menonjol \\
\hline 14 & Krem & Kuning gading & Kuning gading & Kuning gading \\
\hline
\end{tabular}

Keterangan: ekspresi dari karakter yang berwarna abu-abu merupakan keunikan karakter dari masing-masing pisang. $1=$ tinggi batang semu; $2=$ warna batang semu bagian luar; $3=$ bercak batang semu; $4=$ warna bercak; $5=$ kanal tangkai daun; $6=$ lebar daun; $7=$ bentuk jantung; $8=$ bentuk kelopak; $9=$ bentuk ujung kelopak; $10=$ letak buah; $11=$ bentuk buah; $12=$ bentuk ujung buah; $13=$ sisa bunga pada ujung buah; 14= warna daging buah saat matang 
Berdasarkan 39 karakter morfologi yang diamati terdapat beberapa karakter yang tidak menunjukkan adanya keragaman yaitu karakter warna cairan batang, tipe jantung, lebar daun, jumlah buah per sisir, dan keberadaan benih. Artinya semua genotipe pisang yang diamati memiliki skor yang sama atau termasuk dalam kelompok yang sama pada kelima karakter tersebut, sedangkan pada karakter yang lain, variasi terlihat jelas baik pada karakter batang semu, daun, bunga maupun buah.

Tabel 1 menunjukkan perbedaan karakter morfologi yang terlihat jelas pada karakter batang semu yang meliputi tinggi, warna batang semu bagian luar, bercak, dan warna bercak. Berdasarkan hasil pengamatan diketahui bahwa terdapat perbedaan pada pisang Awak dan kepok yang masing-masing tinggi tanaman pisang yang ditemukan memiliki tinggi 4,5 $\mathrm{m}$ dan $6,5 \mathrm{~m}$ sedangkan genotipe pisang lainnya memiliki ukuran antara 2,1-3 m. Menurut Cahyono (2002), pada umumnya tanaman pisang memiliki tinggi berkisar antara 2-9 m. Berdasarkan pengamatan karakter batang semu pada warna batang bagian luar diketahui bahwa dari 8 genotipe pisang yang ditemukan diketahui bahwa terdapat perbedaan pada pisang Lilit tandan dan Kepok memiliki warna yang berbeda daripada yang lain, yang masing-masing warnanya ialah merah keunguan dan hijau tua. Hal yang sama juga ditunjukkan oleh bercak yang ada pada batang semu, dimana warna, jumlah dan ukuran bercak terjadi variasi disetiap genotipe pisang yang ditemukan, namun satu-satunya yang berbeda ialah pada pisang Barangan yang memiliki bercak yang lebar dan pisang Lilit tandan yang memiliki bercak berwarna coklat. Warna yang timbul pada batang semu terjadi karena tanaman pisang dalam proses metabolisme akan menghasilkan pigmen warna dan setiap jenis pisang memiliki gen pigmen warna yang berbeda sehingga tanaman pisang akan menampilkan warna yang berbeda sebagai ciri khas (Siddiqah, 2002).

Perbedaan morfologi pada karakter daun yang terlihat jelas meliputi lebar daun dan bentuk kanal. Berdasarkan hasil pengamatan diketahui bahwa terdapat perbedaan pada pisang Barangan memiliki bentuk kanal yang terbuka dengan batas menyebar. Lalu lebar daun diketahui bahwa terdapat perbedaan pada pisang Barangan, Lilit tandan, dan pisang Awak yang masing-masing memiliki lebar daun $70 \mathrm{~cm}, 50$ $\mathrm{cm}$, dan $65 \mathrm{~cm}$. Lebar daun untuk pisang lainnya memiliki kisaran $52 \mathrm{~cm}$ hingga $63 \mathrm{~cm}$. Data tersebut menunjukkan bahwa pada karakter morfologi daun, karakter kuantitatif pada daun pisang mengalami keragaman untuk setiap genotipe pisang dan untuk karakter kualitatif mengalami keragaman juga antar genotipe pisang yang ditemukan.

Berdasarkan hasil pengamatan terhadap organ generatif pisang pada jantung diketahui bahwa perbedaan karakter morfologi yang terlihat jelas pada bentuk jantung, bentuk kelopak, dan bentuk ujung kelopak. Bentuk jantung pisang terdapat perbedaan pada pisang Tanduk yang benbentuk lonjong. Pisang Kepok memiliki perbedaan pada bentuk kelopak yang medium. Pisang Awak terdapat perbedaan pada bentuk ujung kelopak yang berbentuk tumpul. Hasil pengamatan terhadap organ generatif pisang pada buah diketahui terdapat perbedaan pada letak buah, bentuk buah, bentuk ujung buah, sisa bunga pada ujung buah, dan warna daging buah saat matang. Pisang Banten memiliki perbedaan bila dibandingkan dengan pisang lainnya pada karakter letak buah yang tegak lurus terhadap tangkai dan bentuk buah yang lurus. Pisang Tanduk memiliki perbedaan bila pada karakter bentuk ujung buah yang menunjuk panjang dan karakter sisa bunga pada ujung buah yang dasarnya menonjol. Pisang Raja memiliki perbedaan dibanding pisang lainnya pada karakter bentuk ujung buah yang menunjuk. Pisang Nangka memiliki perbedaan dibanding pisang lainnya pada karakter warna daging saat matang yang berwarna krem. Menurut Ambarita et al. (2015), organ generatif pada tanaman pisang sangat dipengaruhi oleh faktor genetik dan setiap kultivar pisang memiliki keunikan dengan kultivar pisang yang lain. Hal tersebut menunjukkan bahwa tanaman pisang masih tergolong dalam kelompok yang sama sehingga setiap jenis pisang akan sulit dibedakan berdasarkan karakter morfologi organ generatif. Keragaman morfologi pada karakter buah yang ditemukan memberikan hasil karakter yang beragaman. Keragaman terjadi pada karakter jumlah sisir per tandan, jumlah buah pertandan, bentuk buah, panjang buah, warna kulit matang dan rasa. Sedangkan genotipe pisang yang memiliki karakter yang sangat berbeda dengan genotipe pisang lainnya adalah pisang Raja dan pisang Tanduk.

Menurut Mujiyo et al. (2017), tanaman pisang umumnya dapat tumbuh optimal dan berproduksi secara optimal di daerah yang memiliki ketinggian antara 400-600 mdpl. Namun hal yang berbeda ditunjukkan pada hasil pengamatan dengan tanaman pisang yang tumbuh di dataran rendah. Tanaman pisang yang tumbuh di dataran rendah cenderung memiliki warna lebih muda dibandingkan dengan tanaman pisang yang tumbuh di dataran yang lebih tinggi. Hal tersebut terjadi karena pada dataran tinggi memiliki jumlah $\mathrm{CO} 2$ yang relatif lebih kecil dibandingkan dengan dataran rendah, sehingga tumbuhan yang tumbuh pada dataran tinggi cenderung memiliki jumlah klorofil yang lebih banyak daripada tumbuhan yang hidup di dataran rendah. Menurut Betriliza (2006), semakin banyak klorofil yang dimiliki oleh suatu tanaman maka warna daun akan semakin pekat. Selain itu, variasi pada warna suatu jenis tanaman dapat dipengaruhi oleh keadaan tempat tumbuhnya dan erat sekali 
hubungannya dengan persediaan makanan dan penyinaran (Tjitrosoepomo, 2010). Tanaman pisang merupakan tanaman yang peka terhadap lingkungan sehingga lingkungan sangat berpengaruh pada penampilan tanaman pisang. Selain itu faktor genetik juga sangat berpengaruh terhadap penampilan tanaman pisang. Menurut Suranto (2001), apabila faktor genetik lebih kuat memberikan pengaruh daripada faktor lingkungan maka tanaman yang berada pada tempat yang berlainan tidak akan menunjukkan variasi morfologi. Sebaliknya apabila faktor genetik lebih lemah daripada faktor lingkungan maka tanaman yang ditanam pada kondisi lingkungan yang berbeda akan memiliki morfologi yang bervariasi. Adanya variasi terhadap karakter yang dimiliki oleh setiap genotipe pisang dipengaruhi oleh faktor genetik, lingkungan dan interaksi antar kedua faktor tersebut serta faktor bias pada saat melakukan pengamatan di lapangan.

Tabel 2. Hasil Analisis Indeks Keanekaragaman dan Indeks Dominansi di 14 Desa

\begin{tabular}{lcc}
\hline Lokasi Desa & H' & C \\
\hline Secanggang & 1.38 & 0.25 \\
Selontong & 1.35 & 0.26 \\
Teluk & 1.56 & 0.22 \\
Telaga Jernih & 1.58 & 0.20 \\
Karang Gading & 1.45 & 0.27 \\
Suka Mulia & 1.03 & 0.37 \\
Kepala Sungai & 1.36 & 0.25 \\
Karang anyar & 1.74 & 0.18 \\
Tanjung Ibus & 0.95 & 0.44 \\
Sungai Ular & 0.00 & 1.00 \\
Kebun Kelapa & 0.69 & 0.50 \\
Perkotaan & 1.54 & 0.22 \\
Cinta Raja & 1.03 & 0.37 \\
Hinai Kiri & 0.00 & 1.00 \\
\hline
\end{tabular}

Keterangan: H': Indeks Keanekaragaman, C: Indeks Dominansi

Berdasarkan hasil analisis keanekaragaman pada Tabel 2 diketahui bahwa Desa Karang anyar memiliki indeks keanekaragaman (H') yang paling tinggi yaitu sebesar 1,74 sedangkan yang paling kecil yaitu Desa Sungai ular dan Hinai kiri masing-masing sebesar 0,00. Hal tersebut menunjukkan bahwa pada Desa Karang anyar memiliki keanekaragaman tanaman pisang yang tinggi. keanekaragaman itu terlihat dari banyaknya genotipe pisang yang ditemukan di desa tersebut namun tidak ditemukan di desa yang lain. Rata-rata desa yang diamati memiliki nilai indeks keanekaragaman lebih dari 1 yang artinya bahwa keanekaragaman yang ada di daerah tersebut tergolong sedang. Menurut Setiadi (2005), kriteria indeks keanekaragaman menunjukkan, jika $\mathrm{H}^{\prime}>3$ berarti keanekaragaman spesies tinggi atau melimpah, $1<\mathrm{H}^{\prime}>3$ berarti keanekaragaman spesies sedang dan $\mathrm{H}^{\prime}<1$ berarti keanekaragaman spesies rendah atau sedikit. Keanekaragaman spesies yang rendah atau sedikit menunjukkan bahwa ekosistem yang ada pada daerah tersebut tergolong buruk, sebaliknya keanekaragaman spesies yang tinggi atau melimpah menunjukkan bahwa ekosistem yang ada pada daerah tersebut tergolong baik (Wijana, 2014). Desa yang memiliki nilai keanekaragaman kurang dari 1 adalah desa Tanjung ibus, Sungai ular, Kebun kelapa, dan desa Hinai kiri.

Indeks dominansi yang didapatkan dari hasil analisis menunjukkan hasil yang berlawanan dengan hasil indeks keanekaragaman. Indeks dominansi yang memiliki nilai tertinggi terdapat pada Desa Sungai ular dan desa Hinai kiri, lalu yang terendah pada Desa Karang anyar dan desa Telaga jernih. Hal tersebut menunjukkan bahwa semakin tinggi nilai indeks dominansi maka akan menunjukkan dominansi atau keseragaman dari kultivar pisang. Menurut Hilwan dan Masyrafina (2015), indeks dominansi akan menunjukkan dominansi atau tingkat penguasaan spesies-spesies di dalam suatu komunitas. Besarnya nilai indeks dominansi ditentukan oleh besarnya luas bidang dasar dan jumlah spesies yang menempati suatu kawasan tertentu (Kasim, 2012). Hasil analisis sesuai dengan teori di mana ketika keanekaragaman tinggi maka dominansi akan rendah karena semakin tinggi tingkat dominansi menunjukkan adanya spesies yang mendominansi suatu areal sehingga akan menurunkan keanekaragaman ekosistem tersebut. Dominansi yang tinggi di desa Sungai ular dan desa Hinai kiri dikarenakan daerah tersebut banyak petani yang menanam jenis pisang yang sama atau bisa dibilang hanya 1 jenis saja. Daerah dengan keanekaragaman yang tinggi menunjukkan bahwa daerah tersebut masih memiliki lingkungan yang baik untuk ditumbuhi oleh tanaman pisang sehingga daerah tersebut dapat ditumbuhi dengan kultivar pisang yang beragam. Kultivar pisang yang tumbuh beragam dapat dijadikan sebagai sumber plasma nutfah dan sumber dari keragaman genetik. Keragaman genetik mempunyai peran yang sangat penting dalam program pemuliaan, karena optimalisasi perolehan genetik akan sifat-sifat tertentu dapat dicapai apabila cukup peluang untuk melakukan seleksi gen terhadap sifat yang diinginkan (Mashudi, 2006). Oleh sebab itu keanekaragaman tanaman pisang yang ada di Kecamatan Secanggang harus dijaga keberadaannya dan pelestarian tanaman pisang sangat perlu untuk dilakukan agar tidak ada spesies pisang yang punah.

\section{Kesimpulan}

1. Tanaman pisang di Kecamatan Secanggang, terdapat 8 genotipe yaitu Pisang Barangan, Pisang Nangka, Pisang Banten, Pisang Lilit Tandan, Pisang Kepok, Pisang Tanduk, Pisang Awak, dan Pisang Raja. Pisang yang ditemukan ini memiliki karakter morfologi yang bervariasi. 
2. Keanekaragaman tanaman pisang di Kecamatan Secanggang termasuk tingkat sedang dengan nilai indeks keanekaragaman (H') 0-1.74 dan nilai indeks dominansi (C) 0.18-1.

\section{Daftar Pustaka}

Ambarita, M.D.Y, E.S. Bayu dan H. Setiado. 2015. Identifikasi Morfologi Pisang (Musa spp) di Kabupaten Deli Serdang. Agroekoteknologi 4(1): 1991- 1924.

Badan Pusat Statistik (BPS). 2020. Produksi Tanaman Pisang Seluruh Provinsi. Diakses dari www.bps.go.id pada tanggal 20 Februari 2020.

Betriliza. 2006. Inventarisasi dan Karakterisasi Morfologi Mangga (Mangifera odorata Griff) di Kecamatan Suliki Kabupaten Lima Puluh Kota. Skripsi Fakultas Pertanian Universitas Andalas. Tidak dipublikasikan.

Cahyono, B. 2002. Pisang Usaha Tani dan Penanganan Pascapanen. Kanisius, Yogyakarta.

Hilwan, I dan I. Masyrafina. 2015. Keanekaragaman Jenis Tumbuhan Bawah di Gunung Papandayan Bagian Timur, Garut, Jawa Barat. Silvikultur Tropika 6(2): 119-125.

IPGRI - INIBAP / CIRAD. 1996. Discriptors for banana (Musa Spp.). International Plant Genetic Resources Institute. Rome, Italy.

Jumari dan A. Pudjoarinto. 2000. Kekerabatan fenotik kultivar pisang di Jawa. Biologi (9): 531542.

Kasim, S. 2012. Nilai Penting dan Keanekaragaman Hayati Hutan Lindung Wakonti DAS Baubau. Agriplus 22(2): 231-240.

Magurran, A.E.1998. Ecological Diversity and It's Measurement.Princeton University Press, New Jersey.

Mashudi. 2006. Peran Konsevasi Genetik dan Pemuliaan Pohon Terhadap Pembangunan Hutan Tanaman. Balai Besar Penelitian Bioteknologi dan Pemuliaan Tanaman Hutan, Yogyakarta.

Mujiyo, H. Widijanto, A. Herawati, F. Rochman dan R. Rafirman. 2017. Potensi Lahan Untuk Budidaya Pisang di Kecamatan Jenawi Karanganyar. Journal of Sustainable Agriculture 32(2): 142-148.

Prasetyo, J. dan Sudiono. 2004. Pemetaan Persebaran Penyakit Bunchy Top pada Tanaman Pisang di Provinsi Lampung. J. Hama dan Penyakit Tumbuhan Tropika 5(2): 94-101.

Rusdiansyah, D. 2013. Potensi dan Peluang Investasi serta Permasalahan Komoditi Pisang di Kalimantan Timur. Badan Perijinan Penanaman Modal Daerah Provinsi Kalimantan Timur.

Setiadi, D. 2005. Keanekaragaman Spesies Tingkat Pohon di Taman Wisata Alam Ruteng, Nusa Tenggara Timur. Biodiversitas 6(2): 118-122.
Siddiqah, M. 2002. Biodiversitas dan Hubungan Kekerabatan Berdasarkan Karkater Morfologi berbagai Plasma Nutfah Pisang. IPB, Bogor.

Sukartini, 2006. Pengelompokan Aksesi Pisang Menggunakan Karakter Morfologi IPGRI. J. Hort 17(1): 26-33.

Suranto. 2001. Pengaruh Lingkungan Terhadap Bentuk Morfologi Tumbuhan. Enviro 1(2): 772775.

Tjitrosoepomo, G. 2010. Morfologi Tumbuhan. UGM Press, Yogyakarta.

Wijana, N. 2014. Analisis Komposisi dan Keanekaragaman Spesies Tumbuhan di Hutan Desa Bali Aga Tigawasa, Buleleng-Bali. Jurnal Sains dan Teknologi 3(1): 288-299. 